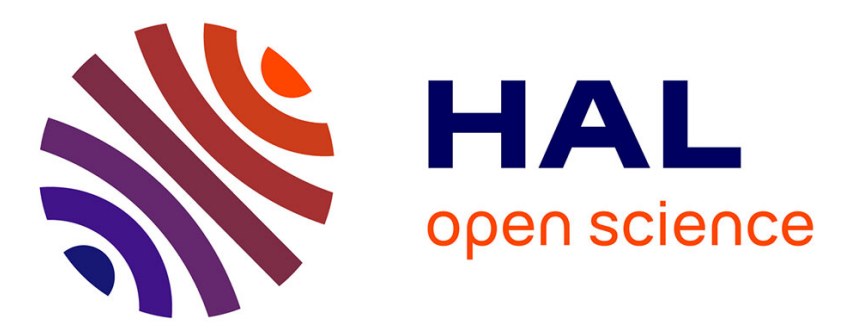

\title{
Modified lipoproteins provide lipids that modulate dendritic cell immune function
}

Laure Perrin-Cocon, Olivier Diaz, Patrice André, Vincent Lotteau

\section{To cite this version:}

Laure Perrin-Cocon, Olivier Diaz, Patrice André, Vincent Lotteau. Modified lipoproteins provide lipids that modulate dendritic cell immune function. Biochimie, 2013, 95 (1), pp.103-8. inserm02442216

\section{HAL Id: inserm-02442216 https://www.hal.inserm.fr/inserm-02442216}

Submitted on 16 Jan 2020

HAL is a multi-disciplinary open access archive for the deposit and dissemination of scientific research documents, whether they are published or not. The documents may come from teaching and research institutions in France or abroad, or from public or private research centers.
L'archive ouverte pluridisciplinaire $\mathbf{H A L}$, est destinée au dépôt et à la diffusion de documents scientifiques de niveau recherche, publiés ou non, émanant des établissements d'enseignement et de recherche français ou étrangers, des laboratoires publics ou privés. 
Modified lipoproteins provide lipids that modulate dendritic cell immune function

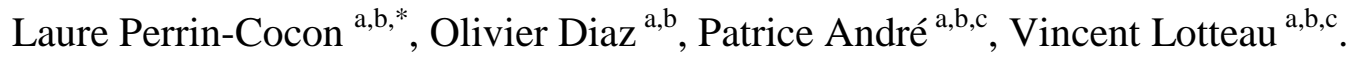

${ }^{\text {a }}$ Université de Lyon, France

${ }^{\mathrm{b}}$ Inserm, U851, 21 Avenue Tony Garnier, Lyon, F-69365, France

${ }^{c}$ Hospices Civils de Lyon, Laboratoire de Virologie, Hôpital de la Croix Rousse, France.

* Corresponding author: Dr. L. Perrin-Cocon, laure.perrin@ inserm.fr

Inserm U851, 21 av. Tony Garnier, 69365 Lyon Cedex 7

Tel: +33437282447

Fax: +33437282341

Key Words:

Lipoproteins, Dendritic Cells, Immune Response, Atherosclerosis, Hepatitis C Virus infection

Abbreviations: Apo, apolipoprotein; DC, dendritic cells; FFA, free fatty acid; HCV, hepatitis $\mathrm{C}$ virus; HDL, high-density lipoproteins; HETE, hydroxyeicosatetraenoic acid; hGX-sPLA 2 , human group $\mathrm{X}-\mathrm{sPLA}_{2}$; HODE, hydroxyoctadecadienoic acid; IDL, intermediate-density lipoproteins; LCAT, lecithin-cholesterol acyltransferase; LDL, low-density lipoproteins; LPC, lysophosphatidylcholine; LPS, lipopolysaccharide; LVP, lipo-viral-particle; oxLDL, oxidized LDL; PAF-AH, platelet-activating factor-acetyl-hydrolase; PAPC, 1-palmitoyl-2arachidonoyl-sn-glycero-3-phosphorylcholine; PC, phosphatidylcholine; PLPC,1-palmitoyl-2linoleyl-sn-glycero-3-phosphorylcholine; PON, paraoxonase; PPAR, peroxisome-proliferator activated receptor; $\mathrm{sPLA}_{2}$ secreted phospholipase $\mathrm{A}_{2}$; TLR, toll-like receptor; Tr1, regulatory T cells type 1; VLDL, very low-density lipoproteins; 


\section{Abstract}

Both physiological and pathological situations can result in biochemical changes of lowdensity lipoproteins (LDL). Because they can deliver signals to dendritic cells (DC), these modified lipoproteins now appear as regulators of the immune response. Among these modified lipoproteins, oxidized LDL (oxLDL) that accumulate during inflammatory conditions have been extensively studied. Numerous studies have shown that oxLDL induce the maturation of DC, enhancing their ability to activate IFN $\gamma$ secretion by $\mathrm{T}$ cells. LDL treated by secreted phospholipase $\mathrm{A}_{2}$ also promote DC maturation. Among the bioactive lipids generated by oxidation or phospholipase treatment of LDL, lysophosphatidylcholine (LPC) and some saturated fatty acids induce DC maturation whereas some unsaturated fatty acids or oxidized derivatives have opposite effects. Among other factors, the nuclear receptor peroxisome-proliferator activated receptor $\gamma(\operatorname{PPAR} \gamma)$ plays a crucial role in this regulation. Non-modified lipoproteins also contribute to the regulation of DC function, suggesting that the balance between native and modified lipoproteins, as well as the biochemical nature of the LDL modifications, can regulate the activation threshold of DC. Here we discuss two pathological situations in which the impact of LDL modifications on inflammation and immunity could play an important role. During atherosclerosis, modified LDL accumulating in the arterial intima may interfere with DC maturation and function, promoting a Th1 immune response and a local inflammation favoring the development of the pathology. In patients chronically infected, the hepatitis $\mathrm{C}$ virus (HCV) interferes with lipoprotein metabolism resulting in the production of infectious modified lipoproteins. These lipo-viralparticles (LVP) are modified low-density lipoproteins containing viral material that can alter DC maturation and affect specific toll-like receptor signaling. In conclusion, lipoprotein 
modifications play an important role in the regulation of immunity by delivering signals of danger to DC and modulating their function.

1. Introduction

Lipoproteins are essential lipid carriers in the blood that are secreted by the liver and the intestine. Chylomicrons secreted by enterocytes after fat diet absorption, transport lipids from the gut to the liver. After rearrangement of endogenous and exogenous lipids, hepatocytes secrete very low-density lipoproteins (VLDL). The transformation of VLDL in the circulation gives rise to particles of smaller size, with intermediate to low density (intermediate-density lipoproteins, IDL and low-density lipoproteins, LDL). High-density lipoproteins (HDL) synthesis requires the secretion of apolipoprotein (Apo) A-I by intestine and liver cells and the gradual extracellular lipidation of nascent HDL by lipid transfer (mainly phospholipids and cholesterol) from the peripheral tissues and other lipoproteins. HDL play an important role in the reverse cholesterol transport from the peripheral tissues to the liver [1].

Lipoproteins are constantly submitted to oxidative modifications and this process needs to be tightly regulated. During non-pathological conditions, the oxidative modifications of LDL are under the strict control of enzymes associated to native LDL and HDL. Paraoxonase (PON1) and platelet-activating factor acetylhydrolase (PAF-AH), especially, are two enzymes carried by lipoproteins that prevent the accumulation of oxidized low-density lipoproteins (oxLDL) [2-4]. PON1 can inhibit LDL oxidation and destroy various bio-active oxidized phospholipids as well as hydrogen peroxide. PAF-AH is a phospholipase $\mathrm{A}_{2}$ that hydrolyzes short-chain acyl groups and longer chain aldehyde esterified at the sn- 2 position of phospholipids. Both lines of control maintain the constant production of oxLDL below a critical threshold. During 
transient inflammatory conditions, such as the acute phase response, HDL exhibit a decrease in PON1 and PAF-AH and an increase in the copper-carrier ceruloplasmin. The acute phase response is characterized by transient wide changes in the concentration of a large number of plasma proteins, especially by dramatic increase in serum amyloid A (up to a thousand fold) and reduction of albumin concentration which is an important lipid carrier. These changes alter HDL ability to inhibit LDL oxidation and anti-inflammatory HDL become proinflammatory [5], resulting in the accumulation of oxLDL.

Lipoproteins are also submitted to modifications occurring during pathological conditions [5, 6]. OxLDL were first studied for their role in chronic inflammation during atherosclerosis [7]. Further work then indicated that infection as well as inflammation resulted in increased levels of oxLDL [6]. Moreover, lipoproteins can also carry molecules delivered by pathogens. This has been extensively studied for bacterial lipopolysaccharide (LPS) [8]. The hepatitis C virus (HCV) has also the unique property so far, to use the lipoprotein synthesis pathway for its secretion. The viral proteins synthesized in the endoplasmic reticulum interfere with lipoprotein synthesis, resulting in the secretion of modified lipoproteins carrying viral material, named lipo-viral-particles (LVP) [9].

Dendritic cells (DC) are key regulators of the immune system [10]. They are specialized antigen presenting cells that need to be activated, in order to efficiently stimulate naive $\mathrm{T}$ cells and induce their differentiation into polarized effector cells [11]. This polarization depends on the signals they receive from DC by cell to cell contact and by secreted mediators such as cytokines and chemokines. DC activation can be triggered by various signals, including pathogen-associated molecular patterns and endogenous alarm signals associated with tissue damage or inflammation. 


\section{Modulation of DC maturation by modified LDL}

\section{1. oxLDL and phospholipase-treated LDL provide lipid signals regulating DC maturation}

Our team has previously shown that oxLDL induce the maturation of human monocytederived DC in vitro, a process that is inhibited by an excess of native LDL $[12,13]$. Upon oxLDL stimulation, mature DC acquire the ability to stimulate $\mathrm{T}$ cells, inducing the secretion of IL-2 and IFN $\gamma$ but not IL-4, IL-5 and IL-13 by T cells. OxLDL-stimulated DC thus exhibit a pro-Th1 function. The effect of oxLDL on DC maturation has been confirmed by others both for human $[14,15]$ and murine $[16,17]$ DC. Some data also indicate that oxLDL induce the differentiation of murine macrophages into dendritic-like cells [18, 19]. These observations imply that the production of oxLDL can be detected by DC and suggest that accumulation of oxLDL during pathological conditions may interfere with DC activation and function.

Oxidative modifications of LDL are complex processes generating numerous modified lipids such as oxysterols, oxidized phospholipids and fatty acids, and their cleavage products (malondialdehyde, 4-hydroxynonenal, etc...). Lysophosphatidylcholine (LPC), which can reach $40-50 \%$ of the total phosphatidylcholine (PC) content in oxLDL [20], can be generated by oxidation and fragmentation of the polyunsaturated fatty-acid in $s n-2$ position, followed by hydrolysis of the shortened fatty acyl residue by LDL-associated enzymes, such as PAF-AH [21]. Moreover, the lecithin-cholesterol acyltransferase (LCAT) enzyme associated to HDL converts PC into LPC by catalyzing the transfer of a fatty acid from PC to the free hydroxyl group of cholesterol [22]. Oxidized phospholipids with long chain in the $s n-2$ position can be hydrolyzed by the LCAT enzyme $[23,24]$. Some of the LPC molecules can be transferred to albumin that provides lipids to surrounding cells. Moreover, LPC can also be produced by the 
hydrolysis of PC by secreted phospholipases $\mathrm{A}_{2} \quad\left(\mathrm{SPLA}_{2}\right)$ whose secretion is strongly increased during inflammatory conditions. Among the $\mathrm{sPLA}_{2} \mathrm{~s}$, the human group $\mathrm{X}$ (hGX$\left.\mathrm{sPLA}_{2}\right)$ has unique enzymatic properties and binds with high affinity to $\mathrm{PC}$, the major phospholipid of cell membranes and lipoproteins [25]. The treatment of LDL by hGX-sPLA 2 results in the production of high amounts of LPC and free fatty acids, preferentially arachidonic or oleic acid [26]. We have shown that hGX-sPLA 2 -treated LDL induce human monocyte-derived DC maturation, resulting in a characteristic mature DC phenotype and enhanced DC ability to activate IFN $\gamma$ secretion by T cells [27].

The production of LPC is involved in many aspects of the inflammatory response. It is a potent chemoattractant for monocytes [28], phagocytes [29] and T lymphocytes [30, 31]. LPC can activate monocytes and macrophages [32-36]. After intracutaneous injection in humans, it induces local inflammation and leukocyte accumulation at the site of injection [37]. LPC also displays immunoregulatory activities. We reported that LPC is one of the active lipids in oxLDL that induces DC phenotypic and functional maturation resulting in pro-Th1 mature DC stimulating IFN $\gamma$ secretion by T lymphocytes [13]. In mice, LPC has adjuvant properties, increasing the humoral response to sheep erythrocytes [38]. It also initiates both humoral and cellular antigen-specific adaptive responses upon vaccination of mice against several protein antigens $[39,40]$. The alkyl-lysophospholipids that are synthetic analogues of LPC, displayed adjuvant-like properties in delayed-type hypersensitivity [41, 42].

In contrast, some oxidized fatty acids generated during LDL oxidation such as 9/11-HODE and 11/15-HETE, can inhibit DC maturation triggered by oxLDL [43]. Moreover oxidized phospholipids and especially oxidized 1-palmitoyl-2-arachidonoyl-sn-glycero-3phosphorylcholine (oxPAPC) inhibit toll-like receptor (TLR) 2 and 4 signaling, inhibiting DC maturation triggered by Pam3CSK4 and LPS, respectively [44]. This inhibition results mainly from competitive binding to the accessory molecules CD14 and MD2 [45, 46]. 
Therefore, the relative level of activating versus inhibitory lipid mediators in oxLDL probably determines the functional properties of oxLDL. Various species of modified lipids can be detected by DC that have the ability to integrate these signals since they express a wide range of cell membrane receptors binding modified lipoproteins (SR-BI, CD36...) or lipids such as LPC $(\mathrm{GPR} 4 \ldots)$ as well as nuclear receptors such as peroxisome-proliferator activated receptors (PPAR) that bind lipids having penetrated the cells.

\subsection{Regulation of DC function by PPAR $\gamma$}

Numerous nuclear receptors are involved in the control of DC maturation. The lipid-binding nuclear receptor PPAR $\gamma$ has emerged as an important regulator of inflammation and immunity in general and of DC function in particular [47]. Several groups have demonstrated that PPAR $\gamma$ agonists reduce the ability of mature DC to secrete IL-12 and to stimulate a Th1 response of $\mathrm{T}$ cells $[43,48-50]$. Nagy et al. have identified two of the major oxidized fatty acids of oxLDL, 9-HODE and 13-HODE, as endogenous activators of PPAR $\gamma$ [51]. In human monocytes, it was shown that oxLDL and oxidized alkyl-phospholipids of oxLDL induced PPAR $\gamma$-dependent gene transcription [52]. In human DC, synthetic or natural agonists of PPAR $\gamma$ such as 9/13-HODE and 11/15-HETE inhibit the functional maturation of DC induced by oxLDL, preventing the acquisition of a pro-Th1 function [43]. In contrast, DC maturation induced by LPC is associated with an important inhibition of PPAR $\gamma$ activity. Thus PPAR $\gamma$ is involved in the control of LPC-induced DC maturation, although it is not yet clear whether the action of LPC on the nuclear receptor is direct or not [43].

3. Regulation of DC function by native lipoproteins 
As indicated above, native LDL can dose-dependently prevent DC maturation induced by oxLDL or LPC, suggesting that the balance between native and oxidized LDL regulates the activation threshold of DC $[12,13]$. Both LDL and HDL strongly inhibit the pro-Th1 function of mature DC, characterized by their ability to induce IFN $\gamma$ secretion by T cells [53]. HDL, especially, can strongly inhibit the functional maturation of DC stimulated by TLR1/2, TLR2/6 and TLR4 ligands, leading to mature cells devoid of Th1 function. This inhibitory activity of HDL was retained by its phospholipid fraction and the 1-palmitoyl-2-linoleyl-snglycero-3-phosphatidylcholine (PLPC) whereas the dipalmitoyl-sn-glycero-3phosphatidylcholine had no significant effect on DC function [53]. Numerous studies have described the major role of HDL into the control of LDL oxidation, therefore playing an indirect role in the regulation of the immune response. The recent findings described above indicate that HDL also have a direct immunoregulatory function, through some of its phospholipids that can modulate the ability of DC to activate a Th1 response.

\section{Modulation of DC maturation and atherosclerosis}

Atherosclerosis is a chronic inflammatory disease in which modified LDL play an important role, not only because their ingestion by macrophages convert them into foam cells but also because they can interfere with the immune response. Several studies have described the contribution of the immune response in the development of the atherosclerotic plaque (for review see $[54,55])$. Importantly, immune cells such as dendritic and $\mathrm{T}$ cells are found in the arterial intima in close vicinity of accumulating modified-lipoproteins, especially oxLDL. Numerous data indicate that the Th1 immune response, characterized by the secretion of IFN $\gamma$ by $\mathrm{T}$ cells, favors the development of the disease [56-58] whereas the downregulation of Th1 responses reduces atherogenesis [59]. The Th1 immune response may support inflammation 
through the secretion of inflammatory cytokines such as IFN $\gamma$ and increase the recruitment of inflammatory cells. Accordingly, in the experimental model of atherosclerosis $\mathrm{ApoE}^{-/-}$mice, the injection of regulatory $\mathrm{T}$ cells type $1(\mathrm{Tr} 1)$ reduces the production of $\mathrm{IFN} \gamma$ and the development of atherosclerosis [60].

Although, the early events of atherogenesis remain poorly understood, the mechanisms involved in plaque progression are better defined. In the inflamed vascular wall (figure 1), LDL that enter the subendothelial space are modified by pro-oxidant molecules such as reactive oxygen species and/or by ${ }_{3} P L A_{2} s$, resulting in the accumulation of oxidized and hydrolyzed LDL containing various species of modified lipids (oxidized PC and fatty acids, malondialdehyde, 4-hydroxynonenal, LPC and FFA). Among the SPLA $_{2}$ s, group IIA, III, V and $\mathrm{X}$ enzymes have been detected in human and/or mouse atherosclerotic lesions [61-64]. These enzymes have different substrate specificities, lipolytic activities and binding properties therefore exerting various effects on lipoproteins and cells [65-67]. Increased expression of these $\mathrm{SPLA}_{2} \mathrm{~S}$ was correlated to progression of atherosclerosis. Moreover, several studies have shown that human group III, V and X sPLA 2 s directly induce DC maturation $[27,68,69]$.

The modified lipoproteins and lipids act on smooth muscle cells and endothelial cells, contributing to the secretion of chemokines and the increased expression of adhesion molecules that favor monocyte recruitment $[61,70,71]$. Monocytes entering the tissue can differentiate into macrophages or DC depending on environmental conditions [72]. Internalization of oxLDL or phospholipase-treated LDL by macrophages converts them into foam cells that are a hallmark of atherosclerosis $[51,61,63]$. Both oxLDL and phospholipasetreated LDL can deliver instructive molecules such as LPC [12, 13, 27, 43], resulting in proTh1 mature DCs that could contribute to the development of the atherosclerotic plaque in vivo. 
During atherogenesis, the accumulation of modified LDL in the arterial wall may trigger an immune response that can participate in the Th1-oriented profile of cytokines observed in the atherosclerotic lesion and contribute to the pathology. Further work is needed to understand how DC integrate the lipid signals provided by lipoproteins and to better determine the molecular pathways involved in the modulation of their functional maturation.

\section{Modulation of DC function by LVP of HCV chronically-infected patients}

HCV infection leads to chronicity in $80 \%$ of the patients, resulting in a specific pathophysiology characterized by glucose and lipid metabolism dysfunctions (i.e. insulinresistance, reduced serum levels of apoB, triglyceride accumulation in hepatocytes) [73]. In infected hepatocytes, HCV proteins are synthetized in the endoplasmic reticulum and the virus takes advantage of lipoprotein biosynthesis for its assembly and secretion $[9,74]$. The interference between viral and lipoprotein assembly results in the secretion of hybrid particles composed of lipoprotein and viral material and forming a heterogeneous population of lipoviral-particles (LVP) (figure 2A). This offers to HCV the possibility to enter the cells via the widely expressed receptors of lipoproteins $[75,76]$. LVP have been assessed in all HCVchronically infected patients tested [76-80]. The very large majority of LVP are subviral particles, harboring a triglyceride-rich lipoprotein content and viral envelopes glycoproteins that outnumber the infectious particles containing both viral capsids and envelopes [81, 82].

Therefore these particles are peculiar modified lipoproteins formed during viral infection. LVP are detected by the immune system since the particles isolated from the blood of the patients are covered with natural anti-envelop antibodies. However, these are not neutralizing antibodies since LVP can be internalized by the LDL receptor [76]. Moreover, LVP interfere with the maturation of DC induced by TLR4 stimulation. Although LVP-treated DC display a normal mature phenotype upon TLR4 stimulation, they produce less inflammatory cytokines 
and have disabled capacities to stimulate IFN $\gamma$ secretion by $\mathrm{T}$ lymphocytes, whereas they induce the production of Th2-type cytokines, IL-5 and IL-13 [83]. The analysis of the signaling pathways involved in this Th2 shift of DC function has highlighted the implication of the MAP-Kinases ERK and p38 [84]. LVP treatment results in an increased and sustained phosphorylation of ERK in mature DC and the inhibition of the MEK/ERK pathway restores the ability of DC to induce IFN $\gamma$ secretion by T cells [83] (fig. 2B).

Interestingly, DC derived from monocytes of HCV chronically-infected patients also present a deficient Th1 function, specifically after stimulation by TLR4 ligand, and not after stimulation by TLR1/2, TLR2/6 or TLR3 ligands [85]. The Th1 function of these DC can be restored by the treatment of cells with an inhibitor of the MEK/ERK pathway prior to TLR4 stimulation [85]. Our results also indicate that monocytes isolated from HCV-chronically infected patients have an elevated state of activation, secreting more cytokines compared to control monocytes [85]. This monocyte activation may be induced in patients either by circulating LVP or other circulating factors such as inflammatory cytokines (fig. 2B). This alteration of monocytes blocks the acquisition of a normal Th1 function upon DC differentiation, by interfering specifically with the TLR4 pathway. This selective defect of DC derived from HCV chronically-infected patients is in agreement with the absence of reported immunodeficiency of the patients. An interesting possibility is that this host-pathogen interference may play a role in the chronicity of $\mathrm{HCV}$ infection.

\section{Conclusions}

Lipoproteins are important regulators of DC maturation. During non-pathological situations, native LDL and HDL present in high amount may prevent DC activation. In contrast, during pathological situations, the increase in modified lipoproteins and the concomitant decrease in 
native lipoproteins could favor DC maturation. In inflamed tissues such as the vascular wall during atherosclerosis, the accumulation of lipoproteins modified by oxidation and/or hydrolysis by $\mathrm{SPLA}_{2}$ favors DC maturation and the acquisition of a pro-Th1 function that could participate in the development of the atheroma. Among the lipid mediators generated under these conditions, LPC revealed as a major inducer of a pro-Th1 maturation of DC and fatty acids could modulate positively or negatively DC functional maturation according to their nature. During chronic infection by HCV, LVP are produced in the form of hybrid lipoproteins carrying viral components interfering with DC maturation and function. DC differentiated from monocytes of $\mathrm{HCV}$-infected patients present a disabled Th1 response upon TLR4 stimulation that could be induced by circulating LVP. These virus-modified lipoproteins are likely to play a role in viral escape to the immune system. 


\section{Acknowledgements}

This work was supported by the Institut National de la Santé et de la Recherche Médicale

(Inserm) and the Agence National de Recherches sur le Sida et les hépatites virales (ANRS), grant HC EP 05. 


\section{References}

[1] G.F. Lewis, D.J. Rader, New insights into the regulation of HDL metabolism and reverse cholesterol transport, Circ Res 96 (2005) 1221-1232.

[2] A.D. Watson, M. Navab, S.Y. Hama, A. Sevanian, S.M. Prescott, D.M. Stafforini, T.M. McIntyre, B.N. Du, A.M. Fogelman, J.A. Berliner, Effect of platelet activating factor-acetylhydrolase on the formation and action of minimally oxidized low density lipoprotein, J Clin Invest 95 (1995) 774-782.

[3] A.D. Watson, J.A. Berliner, S.Y. Hama, B.N. La Du, K.F. Faull, A.M. Fogelman, M. Navab, Protective effect of high density lipoprotein associated paraoxonase. Inhibition of the biological activity of minimally oxidized low density lipoprotein, J Clin Invest 96 (1995) 2882-2891.

[4] M.I. Mackness, S. Arrol, P.N. Durrington, Paraoxonase prevents accumulation of lipoperoxides in low-density lipoprotein, FEBS Lett 286 (1991) 152-154.

[5] B.J. Van Lenten, S.Y. Hama, F.C. de Beer, D.M. Stafforini, T.M. McIntyre, S.M. Prescott, B.N. La Du, A.M. Fogelman, M. Navab, Anti-inflammatory HDL becomes pro-inflammatory during the acute phase response. Loss of protective effect of HDL against LDL oxidation in aortic wall cell cocultures, J Clin Invest 96 (1995) 2758-2767.

[6] R.A. Memon, I. Staprans, M. Noor, W.M. Holleran, Y. Uchida, A.H. Moser, K.R. Feingold, C. Grunfeld, Infection and inflammation induce LDL oxidation in vivo, Arterioscler Thromb Vasc Biol 20 (2000) 1536-1542.

[7] J.L. Witztum, D. Steinberg, Role of oxidized low density lipoprotein in atherogenesis, J Clin Invest 88 (1991) 1785-1792.

[8] A.M. Barcia, H.W. Harris, Triglyceride-rich lipoproteins as agents of innate immunity, Clinical infectious diseases : an official publication of the Infectious Diseases Society of America 41 Suppl 7 (2005) S498-503.

[9] R. Bartenschlager, F. Penin, V. Lohmann, P. Andre, Assembly of infectious hepatitis C virus particles, Trends in microbiology 19 (2011) 95-103.

[10] R.M. Steinman, H. Hemmi, Dendritic cells: translating innate to adaptive immunity, Current topics in microbiology and immunology 311 (2006) 17-58.

[11] A. Mazzoni, D.M. Segal, Controlling the Toll road to dendritic cell polarization, J Leukoc Biol 75 (2004) 721-730.

[12] L. Perrin-Cocon, F. Coutant, S. Agaugue, S. Deforges, P. Andre, V. Lotteau, Oxidized lowdensity lipoprotein promotes mature dendritic cell transition from differentiating monocyte, J Immunol 167 (2001) 3785-3791.

[13] F. Coutant, L. Perrin-Cocon, S. Agaugue, T. Delair, P. Andre, V. Lotteau, Mature dendritic cell generation promoted by lysophosphatidylcholine, J Immunol 169 (2002) 1688-1695.

[14] C.J. Alderman, P.R. Bunyard, B.M. Chain, J.C. Foreman, D.S. Leake, D.R. Katz, Effects of oxidised low density lipoprotein on dendritic cells: a possible immunoregulatory component of the atherogenic micro-environment?, Cardiovascular research 55 (2002) 806-819.

[15] T. Nickel, D. Schmauss, H. Hanssen, Z. Sicic, B. Krebs, S. Jankl, C. Summo, P. Fraunberger, A.K. Walli, S. Pfeiler, M. Weis, oxLDL uptake by dendritic cells induces upregulation of scavengerreceptors, maturation and differentiation, Atherosclerosis 205 (2009) 442-450.

[16] M. Luchtefeld, C. Grothusen, A. Gagalick, K. Jagavelu, H. Schuett, U.J. Tietge, O. Pabst, K. Grote, H. Drexler, R. Forster, B. Schieffer, Chemokine receptor 7 knockout attenuates atherosclerotic plaque development, Circulation 122 (2010) 1621-1628.

[17] J. Ge, H. Yan, S. Li, W. Nie, K. Dong, L. Zhang, W. Zhu, F. Fan, J. Zhu, Changes in proteomics profile during maturation of marrow-derived dendritic cells treated with oxidized lowdensity lipoprotein, Proteomics 11 (2011) 1893-1902.

[18] L.H. Shen, L. Zhou, B.Y. Wang, J. Pu, L.H. Hu, D.J. Chai, L. Wang, J.Z. Zeng, B. He, Oxidized low-density lipoprotein induces differentiation of RAW264.7 murine macrophage cell line into dendritic-like cells, Atherosclerosis 199 (2008) 257-264. 
[19] H.J. Cho, P. Shashkin, C.A. Gleissner, D. Dunson, N. Jain, J.K. Lee, Y. Miller, K. Ley, Induction of dendritic cell-like phenotype in macrophages during foam cell formation, Physiological genomics 29 (2007) 149-160.

[20] S. Parthasarathy, J. Barnett, Phospholipase A2 activity of low density lipoprotein: evidence for an intrinsic phospholipase A2 activity of apoprotein B-100, Proc Natl Acad Sci U S A 87 (1990) 9741 9745.

[21] U.P. Steinbrecher, P.H. Pritchard, Hydrolysis of phosphatidylcholine during LDL oxidation is mediated by platelet-activating factor acetylhydrolase, J Lipid Res 30 (1989) 305-315.

[22] S. Kunnen, M. Van Eck, Lecithin-cholesterol acyltransferase: old friend or foe in atherosclerosis?, J Lipid Res (2012).

[23] V.S. Subramanian, J. Goyal, M. Miwa, J. Sugatami, M. Akiyama, M. Liu, P.V. Subbaiah, Role of lecithin-cholesterol acyltransferase in the metabolism of oxidized phospholipids in plasma: studies with platelet-activating factor-acetyl hydrolase-deficient plasma, Biochim Biophys Acta 1439 (1999) 95-109.

[24] H. Itabe, R. Hosoya, K. Karasawa, S. Jimi, K. Saku, S. Takebayashi, T. Imanaka, T. Takano, Metabolism of oxidized phosphatidylcholines formed in oxidized low density lipoprotein by lecithincholesterol acyltransferase, Journal of biochemistry 126 (1999) 153-161.

[25] W. Pruzanski, L. Lambeau, M. Lazdunsky, W. Cho, J. Kopilov, A. Kuksis, Differential hydrolysis of molecular species of lipoprotein phosphatidylcholine by groups IIA, V and X secretory phospholipases A(2), Biochim Biophys Acta 1736 (2005) 38-50.

[26] K. Yamamoto, Y. Isogai, H. Sato, Y. Taketomi, M. Murakami, Secreted phospholipase A2, lipoprotein hydrolysis, and atherosclerosis: integration with lipidomics, Anal Bioanal Chem 400 (2011) 1829-1842.

[27] R. Atout, S.A. Karabina, S. Dollet, M. Carreras, C. Payre, P. Andre, G. Lambeau, V. Lotteau, E. Ninio, L. Perrin-Cocon, Human group $X$ secreted phospholipase $A(2)$ induces dendritic cell maturation through lipoprotein-dependent and -independent mechanisms, Atherosclerosis 222 (2012) 367-374.

[28] M.T. Quinn, S. Parthasarathy, D. Steinberg, Lysophosphatidylcholine: a chemotactic factor for human monocytes and its potential role in atherogenesis, Proc Natl Acad Sci U S A 85 (1988) 2805 2809.

[29] K. Lauber, S.G. Blumenthal, M. Waibel, S. Wesselborg, Clearance of apoptotic cells: getting rid of the corpses, Mol Cell 14 (2004) 277-287.

[30] H.F. McMurray, S. Parthasarathy, D. Steinberg, Oxidatively modified low density lipoprotein is a chemoattractant for human T lymphocytes, J Clin Invest 92 (1993) 1004-1008.

[31] C.G. Radu, L.V. Yang, M. Riedinger, M. Au, O.N. Witte, T cell chemotaxis to lysophosphatidylcholine through the G2A receptor, Proc Natl Acad Sci U S A 101 (2004) 245-250.

[32] Q. Jing, S.M. Xin, W.B. Zhang, P. Wang, Y.W. Qin, G. Pei, Lysophosphatidylcholine activates p38 and p42/44 mitogen-activated protein kinases in monocytic THP-1 cells, but only p38 activation is involved in its stimulated chemotaxis, Circ Res 87 (2000) 52-59.

[33] S.S. Ousman, S. David, Lysophosphatidylcholine induces rapid recruitment and activation of macrophages in the adult mouse spinal cord, Glia 30 (2000) 92-104.

[34] T. Ogita, Y. Tanaka, T. Nakaoka, R. Matsuoka, Y. Kira, M. Nakamura, T. Shimizu, T. Fujita, Lysophosphatidylcholine transduces $\mathrm{Ca} 2+$ signaling via the platelet- activating factor receptor in macrophages, Am J Physiol 272 (1997) H17-24.

[35] J. Oestvang, M.W. Anthonsen, B. Johansen, Role of secretory and cytosolic phospholipase A(2) enzymes in lysophosphatidylcholine-stimulated monocyte arachidonic acid release, FEBS Lett 555 (2003) 257-262.

[36] B.Z. Ngwenya, N. Yamamoto, Activation of peritoneal macrophages by lysophosphatidylcholine, Biochim Biophys Acta 839 (1985) 9-15.

[37] A.K. Ryborg, B. Deleuran, H. Sogaard, K. Kragballe, Intracutaneous injection of lysophosphatidylcholine induces skin inflammation and accumulation of leukocytes, Acta Derm Venereol 80 (2000) 242-246.

[38] B.Z. Ngwenya, D.M. Foster, Enhancement of antibody production by lysophosphatidylcholine and alkylglycerol, Proc Soc Exp Biol Med 196 (1991) 69-75. 
[39] L. Perrin-Cocon, S. Agaugue, F. Coutant, P. Saint-Mezard, A. Guironnet-Paquet, J.F. Nicolas, P. Andre, V. Lotteau, Lysophosphatidylcholine is a natural adjuvant that initiates cellular immune responses, Vaccine 24 (2006) 1254-1263.

[40] G. Bach, L. Perrin-Cocon, E. Gerossier, A. Guironnet-Paquet, V. Lotteau, G. Inchauspe, A. Fournillier, Single lysophosphatidylcholine components exhibit adjuvant activities in vitro and in vivo, Clinical and vaccine immunology : CVI 17 (2010) 429-438.

[41] B. Arnold, F.G. Staber, J.F. Miller, Lysolecithin analogs as adjuvants in delayed-type hypersensitivity in mice. II. Studies on the mode of action, Eur J Immunol 9 (1979) 367-370.

[42] B. Arnold, J.F. Miller, H.U. Weltzien, Lysolecithin analogs as adjuvants in delayed-type hypersensitivity in mice. I. Characterization of the adjuvant effect, Eur J Immunol 9 (1979) 363-366.

[43] F. Coutant, S. Agaugue, L. Perrin-Cocon, P. Andre, V. Lotteau, Sensing environmental lipids by dendritic cell modulates its function, J Immunol 172 (2004) 54-60.

[44] S. Bluml, S. Kirchberger, V.N. Bochkov, G. Kronke, K. Stuhlmeier, O. Majdic, G.J. Zlabinger, W. Knapp, B.R. Binder, J. Stockl, N. Leitinger, Oxidized phospholipids negatively regulate dendritic cell maturation induced by TLRs and CD40, J Immunol 175 (2005) 501-508.

[45] C. Erridge, D.J. Webb, C.M. Spickett, Toll-like receptor 4 signalling is neither sufficient nor required for oxidised phospholipid mediated induction of interleukin-8 expression, Atherosclerosis 193 (2007) 77-85.

[46] C. Erridge, S. Kennedy, C.M. Spickett, D.J. Webb, Oxidized phospholipid inhibition of tolllike receptor (TLR) signaling is restricted to TLR2 and TLR4: roles for CD14, LPS-binding protein, and MD2 as targets for specificity of inhibition, J Biol Chem 283 (2008) 24748-24759.

[47] R.A. Daynes, D.C. Jones, Emerging roles of PPARs in inflammation and immunity, Nat Rev Immunol 2 (2002) 748-759.

[48] A. Nencioni, F. Grunebach, A. Zobywlaski, C. Denzlinger, W. Brugger, P. Brossart, Dendritic cell immunogenicity is regulated by peroxisome proliferator-activated receptor gamma, J Immunol 169 (2002) 1228-1235.

[49] C. Faveeuw, S. Fougeray, V. Angeli, J. Fontaine, G. Chinetti, P. Gosset, P. Delerive, C. Maliszewski, M. Capron, B. Staels, M. Moser, F. Trottein, Peroxisome proliferator-activated receptor gamma activators inhibit interleukin-12 production in murine dendritic cells, FEBS Lett 486 (2000) 261-266.

[50] P. Gosset, A.S. Charbonnier, P. Delerive, J. Fontaine, B. Staels, J. Pestel, A.B. Tonnel, F. Trottein, Peroxisome proliferator-activated receptor gamma activators affect the maturation of human monocyte-derived dendritic cells, Eur J Immunol 31 (2001) 2857-2865.

[51] L. Nagy, P. Tontonoz, J.G. Alvarez, H. Chen, R.M. Evans, Oxidized LDL regulates macrophage gene expression through ligand activation of PPARgamma, Cell 93 (1998) 229-240.

[52] S.S. Davies, A.V. Pontsler, G.K. Marathe, K.A. Harrison, R.C. Murphy, J.C. Hinshaw, G.D. Prestwich, A.S. Hilaire, S.M. Prescott, G.A. Zimmerman, T.M. McIntyre, Oxidized alkyl phospholipids are specific, high affinity peroxisome proliferator-activated receptor gamma ligands and agonists, J Biol Chem 276 (2001) 16015-16023.

[53] L. Perrin-Cocon, O. Diaz, M. Carreras, S. Dollet, A. Guironnet-Paquet, P. Andre, V. Lotteau, High-density lipoprotein phospholipids interfere with dendritic cell Th1 functional maturation, Immunobiology 217 (2012) 91-99.

[54] G.K. Hansson, A. Hermansson, The immune system in atherosclerosis, Nat Immunol 12 (2011) 204-212.

[55] A. Niessner, C.M. Weyand, Dendritic cells in atherosclerotic disease, Clin Immunol 134 (2010) 25-32.

[56] S. Gupta, A.M. Pablo, X. Jiang, N. Wang, A.R. Tall, C. Schindler, IFN-gamma potentiates atherosclerosis in ApoE knock-out mice, J Clin Invest 99 (1997) 2752-2761.

[57] J. Frostegard, A.K. Ulfgren, P. Nyberg, U. Hedin, J. Swedenborg, U. Andersson, G.K. Hansson, Cytokine expression in advanced human atherosclerotic plaques: dominance of proinflammatory (Th1) and macrophage-stimulating cytokines, Atherosclerosis 145 (1999) 33-43.

[58] S. Schulte, G.K. Sukhova, P. Libby, Genetically programmed biases in Th1 and Th2 immune responses modulate atherogenesis, Am J Pathol 172 (2008) 1500-1508. 
[59] E. Laurat, B. Poirier, E. Tupin, G. Caligiuri, G.K. Hansson, J. Bariety, A. Nicoletti, In vivo downregulation of $\mathrm{T}$ helper cell 1 immune responses reduces atherogenesis in apolipoprotein $\mathrm{E}$ knockout mice, Circulation 104 (2001) 197-202.

[60] Z. Mallat, A. Gojova, V. Brun, B. Esposito, N. Fournier, F. Cottrez, A. Tedgui, H. Groux, Induction of a regulatory $\mathrm{T}$ cell type 1 response reduces the development of atherosclerosis in apolipoprotein E-knockout mice, Circulation 108 (2003) 1232-1237.

[61] S.A. Karabina, I. Brocheriou, G. Le Naour, M. Agrapart, H. Durand, M. Gelb, G. Lambeau, E. Ninio, Atherogenic properties of LDL particles modified by human group X secreted phospholipase A2 on human endothelial cell function, Faseb J 20 (2006) 2547-2549.

[62] M. Kimura-Matsumoto, Y. Ishikawa, K. Komiyama, T. Tsuruta, M. Murakami, S. Masuda, Y. Akasaka, K. Ito, S. Ishiguro, H. Morita, S. Sato, T. Ishii, Expression of secretory phospholipase A2s in human atherosclerosis development, Atherosclerosis 196 (2008) 81-91.

[63] K. Hanasaki, K. Yamada, S. Yamamoto, Y. Ishimoto, A. Saiga, T. Ono, M. Ikeda, M. Notoya, S. Kamitani, H. Arita, Potent modification of low density lipoprotein by group X secretory phospholipase A2 is linked to macrophage foam cell formation, J Biol Chem 277 (2002) 29116-29124. [64] S.A. Karabina, S. Gora, R. Atout, E. Ninio, Extracellular phospholipases in atherosclerosis, Biochimie 92 (2010) 594-600.

[65] S. Bezzine, R.S. Koduri, E. Valentin, M. Murakami, I. Kudo, F. Ghomashchi, M. Sadilek, G. Lambeau, M.H. Gelb, Exogenously added human group X secreted phospholipase A(2) but not the group IB, IIA, and V enzymes efficiently release arachidonic acid from adherent mammalian cells, $\mathrm{J}$ Biol Chem 275 (2000) 3179-3191.

[66] A.G. Singer, F. Ghomashchi, C. Le Calvez, J. Bollinger, S. Bezzine, M. Rouault, M. Sadilek, E. Nguyen, M. Lazdunski, G. Lambeau, M.H. Gelb, Interfacial kinetic and binding properties of the complete set of human and mouse groups I, II, V, X, and XII secreted phospholipases A2, J Biol Chem 277 (2002) 48535-48549.

[67] E. Valentin, G. Lambeau, Increasing molecular diversity of secreted phospholipases A(2) and their receptors and binding proteins, Biochim Biophys Acta 1488 (2000) 59-70.

[68] L. Perrin-Cocon, S. Agaugue, F. Coutant, A. Masurel, S. Bezzine, G. Lambeau, P. Andre, V. Lotteau, Secretory phospholipase A2 induces dendritic cell maturation, Eur J Immunol 34 (2004) 2293-2302.

[69] G. Giannattasio, D. Fujioka, W. Xing, H.R. Katz, J.A. Boyce, B. Balestrieri, Group V secretory phospholipase A2 reveals its role in house dust mite-induced allergic pulmonary inflammation by regulation of dendritic cell function, J Immunol 185 (2010) 4430-4438.

[70] N. Kume, M.I. Cybulsky, M.A. Gimbrone, Jr., Lysophosphatidylcholine, a component of atherogenic lipoproteins, induces mononuclear leukocyte adhesion molecules in cultured human and rabbit arterial endothelial cells, J Clin Invest 90 (1992) 1138-1144.

[71] S. Gora, S. Maouche, R. Atout, K. Wanherdrick, G. Lambeau, F. Cambien, E. Ninio, S.A. Karabina, Phospholipolyzed LDL induces an inflammatory response in endothelial cells through endoplasmic reticulum stress signaling, Faseb J 24 (2010) 3284-3297.

[72] G.J. Randolph, S. Beaulieu, S. Lebecque, R.M. Steinman, W.A. Muller, Differentiation of monocytes into dendritic cells in a model of transendothelial trafficking, Science 282 (1998) 480-483.

[73] M. Basaranoglu, G. Basaranoglu, Pathophysiology of insulin resistance and steatosis in patients with chronic viral hepatitis, World journal of gastroenterology : WJG 17 (2011) 4055-4062.

[74] V. Icard, O. Diaz, C. Scholtes, L. Perrin-Cocon, C. Ramiere, R. Bartenschlager, F. Penin, V. Lotteau, P. Andre, Secretion of hepatitis C virus envelope glycoproteins depends on assembly of apolipoprotein B positive lipoproteins, PLoS ONE 4 (2009) e4233.

[75] M. Monazahian, I. Bohme, S. Bonk, A. Koch, C. Scholz, S. Grethe, R. Thomssen, Low density lipoprotein receptor as a candidate receptor for hepatitis C virus, J Med Virol 57 (1999) 223 229.

[76] P. Andre, F. Komurian-Pradel, S. Deforges, M. Perret, J.L. Berland, M. Sodoyer, S. Pol, C. Brechot, G. Paranhos-Baccala, V. Lotteau, Characterization of low- and very-low-density hepatitis C virus RNA- containing particles, J Virol 76 (2002) 6919-6928.

[77] D. Bradley, K. McCaustland, K. Krawczynski, J. Spelbring, C. Humphrey, E.H. Cook, Hepatitis C virus: buoyant density of the factor VIII-derived isolate in sucrose, J Med Virol 34 (1991) 206-208. 
[78] S.U. Nielsen, M.F. Bassendine, A.D. Burt, C. Martin, W. Pumeechockchai, G.L. Toms, Association between hepatitis C virus and very-low-density lipoprotein (VLDL)/LDL analyzed in iodixanol density gradients, J Virol 80 (2006) 2418-2428.

[79] S.U. Nielsen, M.F. Bassendine, C. Martin, D. Lowther, P.J. Purcell, B.J. King, D. Neely, G.L. Toms, Characterization of hepatitis C RNA-containing particles from human liver by density and size, J Gen Virol 89 (2008) 2507-2517.

[80] R. Thomssen, S. Bonk, A. Thiele, Density heterogeneities of hepatitis C virus in human sera due to the binding of beta-lipoproteins and immunoglobulins, Med Microbiol Immunol 182 (1993) 329-334.

[81] O. Diaz, F. Delers, M. Maynard, S. Demignot, F. Zoulim, J. Chambaz, C. Trepo, V. Lotteau, P. Andre, Preferential association of Hepatitis C virus with apolipoprotein B48-containing lipoproteins, J Gen Virol 87 (2006) 2983-2991.

[82] C. Scholtes, C. Ramiere, D. Rainteau, L. Perrin-Cocon, C. Wolf, L. Humbert, M. Carreras, A. Guironnet-Paquet, F. Zoulim, R. Bartenschlager, V. Lotteau, P. Andre, O. Diaz, High plasma level of nucleocapsid-free envelope glycoprotein-positive lipoproteins in hepatitis C patients, Hepatology 56 (2012) 39-48.

[83] S. Agaugue, L. Perrin-Cocon, P. Andre, V. Lotteau, Hepatitis C lipo-Viro-particle from chronically infected patients interferes with TLR4 signaling in dendritic cell, PLoS ONE 2 (2007) e330.

[84] S. Agaugue, L. Perrin-Cocon, F. Coutant, P. Andre, V. Lotteau, 1-Methyl-tryptophan can interfere with TLR signaling in dendritic cells independently of IDO activity, J Immunol 177 (2006) 2061-2071.

[85] L. Perrin-Cocon, S. Agaugue, O. Diaz, B. Vanbervliet, S. Dollet, A. Guironnet-Paquet, P. Andre, V. Lotteau, Th1 disabled function in response to TLR4 stimulation of monocyte-derived DC from patients chronically-infected by hepatitis C virus, PLoS ONE 3 (2008) e2260. 
Figures

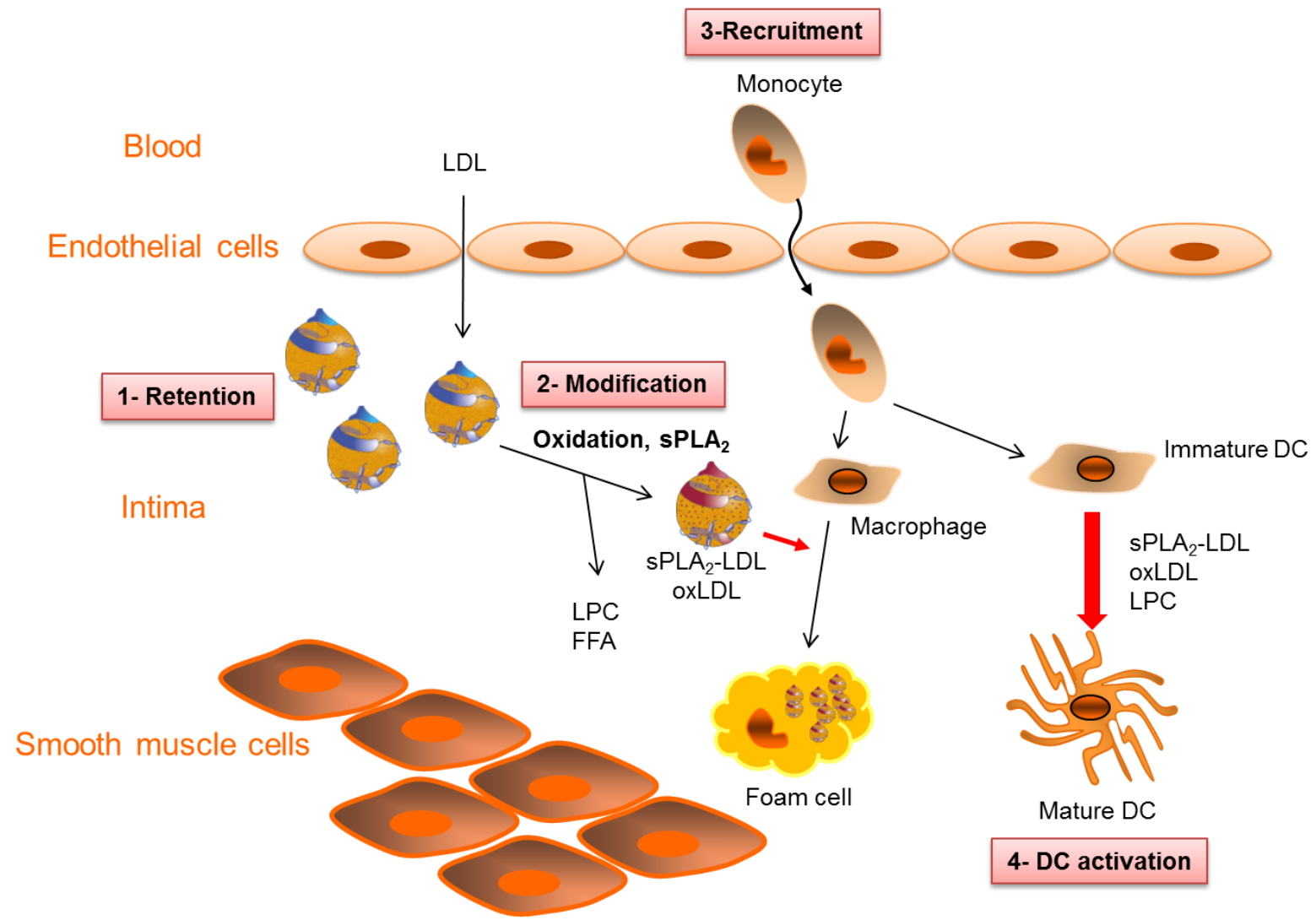

Fig. 1. Modulation of DC maturation by modified LDL during atherosclerosis.

During atherogenesis, LDL entering the subendothelial space are modified by oxidation or sPLA $_{2}$ hydrolysis, generating various lipid mediators such as LPC and free fatty acids. Monocytes entering the inflamed tissue can differentiate into macrophages or DC. More than inducing foam cells generation from macrophages, oxLDL and phospholipase-treated LDL (sPLA 2 -LDL) also induce DC maturation. LPC, fatty acids and oxidized fatty acids have the ability to modulate DC function. 
A

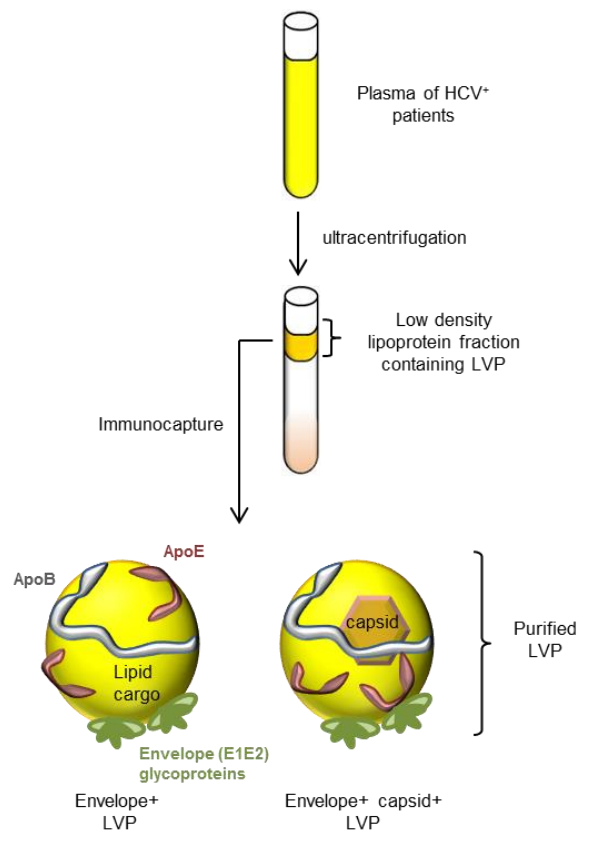

B

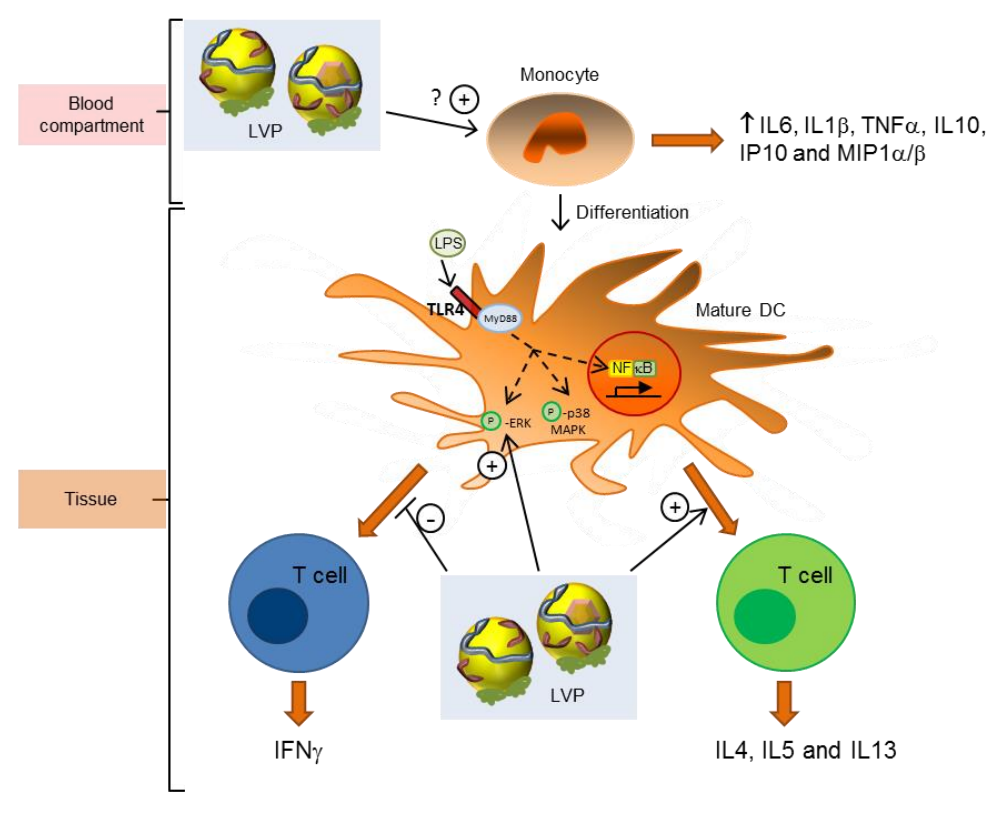

Fig. 2. LVP circulating into the blood of HCV-infected patients interfere with DC maturation.

(A) LVP is a constant feature of HCV chronicity and can be purified by immunocapture from serum low-density-lipoprotein fraction after density gradient ultracentrifugation. LVP fraction contains subviral low-density particles (i.e. $\mathrm{ApoB}^{+}$envelope $^{+}$LVP) and infectious low-density particles (i.e. $\mathrm{ApoB}^{+}$envelope ${ }^{+} \mathrm{HCV}-\mathrm{RNA}^{+}$LVP). (B) LVP could interfere with DC function at several stages. Monocytes isolated from HCV patients secrete increased amounts of IL6, IL1 $\beta$, TNF $\alpha$, IL10, IP10 and MIP1 $\alpha / \beta$ compared with monocytes from healthy donors. LVP may activate monocytes by yet unknown mechanisms. TLR4-stimulated DC derived from HCV patient's monocytes have disabled capacities to stimulate IFN $\gamma$ secretion by $\mathrm{T}$ cells. LVP modulate the function of DC differentiated from monocytes, inducing a Th2 shift of TLR4-stimulated DC function in an ERK and p38 MAP-kinase dependent pathway. 